\title{
Immobilizing Corporate Income Shifting: Should it be Safe to Strip in the Harbour?
}

\author{
Thomas A. Gresik \\ Dirk Schindler \\ Guttorm Schjelderup
}

CESIFO WORKING PAPER NO. 5609

CATEGORY 1: PuBliC FinANCE

NOVEMBER 2015

An electronic version of the paper may be downloaded

- from the SSRN website:

- from the RePEc website:

- from the CESifo website:

WwW.SSRN.com

www.RePEc.org

www.CESifo-group.org/wp 


\title{
Immobilizing Corporate Income Shifting: Should it be Safe to Strip in the Harbour?
}

\begin{abstract}
Many subsidiaries can deduct interest payments on internal debt from their taxable income. By issuing internal debt from a tax haven, multinationals can shift income out of host countries through the interest rates they charge and the amount of internal debt they issue. We show that, from a welfare perspective, thin-capitalization rules that restrict the amount of debt for which interest is tax deductible (safe harbor rules) are inferior to rules that limit the ratio of debt interest to pre-tax earnings (earnings stripping rules), even if a safe harbor rule is used in conjunction with an earnings stripping rule.
\end{abstract}

JEL-Codes: H730, H260, K340.

Keywords: multinational, income-shifting, safe harbor, earnings stripping.

Thomas A. Gresik University of Notre Dame USA - Notre Dame, IN 46556

Thomas.A.Gresik.1@nd.edu
Dirk Schindler Norwegian School of Economics Norway-5045 Bergen dirk.schindler@nhh.no

Guttorm Schjelderup

Norwegian School of Economics

Norway - 5045 Bergen

guttorm.schjelderup@nhh.no

September 2015 


\section{Introduction.}

Earnings stripping is a tactic multinational firms use to shift taxable income from a high-tax country to a low-tax country by financing a subsidiary located in a high-tax country with loans from the parent (internal debt) through a subsidiary located in a low-tax country. Since interest payments on debt are generally tax deductible, the use of internal debt allows multinationals to reduce its overall corporate income tax payments.

In 2014, earnings stripping was at the heart of the contentious debate about corporate inversions. By moving the parent corporation of a multinational from the United States to a country with a lower tax rate (pretty much the rest of the world), the new parent corporation could load up its U.S. subsidiaries with internal debt in order to strip pre-tax income out of the United States. This concern prompted legislators such as Senator Charles Schumer to propose legislation specifically intended to curb earnings stripping activity. ${ }^{2}$

Earnings stripping is also central to the on-going criticisms by a number of OECD countries of the U.S. "Check-The-Box" (CTB) legislation. CTB was passed in 1997 to simplify the process by which a U.S. firm could elect its tax status as a corporation or a partnership. For U.S. multinationals, CTB enables the parent company to structure an affiliate in a host country so that it is treated as a corporation/subsidiary by the host country and as a branch by the United States. The effect of CTB is that the U.S. parent can use internal debt to strip taxable income out of a host country without generating an offsetting tax liability in the United States (as subpart F income). ${ }^{3}$

\footnotetext{
${ }^{2}$ See McKinnon (2014).

${ }^{3}$ Blouin and Krull (2015) provide a more detailed description of the tax implications of CTB.
} 
The amount of interest that a subsidiary of a multinational can deduct from its host country taxable income is determined by the rate of interest applied to its debt and the amount of its debt. Host countries can limit tax-induced income shifting via manipulation of the interest rate on internal debt (a transfer price) by auditing to make sure that the interest rate is in line with what a third-party lender would charge for a comparable risk (i.e., the arm's-length standard). Host countries can also limit the use of income shifting via the amount of debt financing by adopting thin-capitalization rules.

Most countries do not have thin-capitalization rules to inhibit the amount of internal debt financing. Instead, they tend to rely on the arm's-length principle to determine what an independent lender would have been willing to lend to the firm. Among countries that have thin-capitalization rules, most use a type of rule called a safe harbor rule. A safe harbor rule limits the tax deductibility of interest payments if the debt-equity ratio of the subsidiary is too large. ${ }^{4}$ A smaller number of countries use what is called an earnings stripping rule, which limits the tax deductibility of interest payments if the operating subsidiary's interest payments exceed a specified percentage of the subsidiary's pre-tax earnings normally defined as the subsidiary's EBITDA. ${ }^{5}$ The use of earnings stripping rules has emerged in recent years because of the perception that safe harbor rules are ineffective. A few countries use both types of rules, whereby a subsidiary must satisfy either both rules or only one of the rules. Table 1 reports the variation in thin-capitalization rules among 160 countries in $2013 .^{6}$

\footnotetext{
${ }^{4}$ See Blouin et al. (2014) and Table 1.

${ }^{5}$ EBITDA stands for earnings before interest, taxes, depreciation, and amortization.

${ }^{6}$ The data comes primarily from Ernst and Young (2013).
} 


\begin{tabular}{|c|c|c|c|c|c|}
\hline $\begin{array}{c}\text { None or } \\
\text { Arm's- } \\
\text { Length } \\
\text { Regulation }\end{array}$ & $\begin{array}{c}\text { Safe } \\
\text { Harbor }\end{array}$ & $\begin{array}{l}\text { Earnings } \\
\text { Stripping }\end{array}$ & $\begin{array}{c}\text { Safe } \\
\text { Harbor and } \\
\text { Earnings } \\
\text { Stripping }\end{array}$ & $\begin{array}{c}\text { Safe } \\
\text { Harbor or } \\
\text { Earnings } \\
\text { Stripping }\end{array}$ & $\begin{array}{c}\text { Special } \\
\text { Rules }\end{array}$ \\
\hline 100 & 45 & 4 & 2 & 6 & 3 \\
\hline
\end{tabular}

Notable countries that use the arm's length standard without a thincapitalization rule include Austria, Finland, Ireland, India, the Netherlands, and Norway. ${ }^{7}$ Although the number of countries using an earnings stripping rule, alone or in conjunction with a safe harbor rule is small, they include significant economics. The countries using only an earnings stripping rule in 2013 are Germany, Italy, Portugal, and Spain. Denmark and Japan impose both a safe harbor rule and an earnings stripping rule. Bulgaria, France, Guam, Northern Marinana Islands, the United States, and the U.S. Virgin Islands impose an earnings stripping rule and a safe harbor rule but require that only one be satisfied. For France, a company need only satisfy one of the rules. For Bulgaria, the United States, and its affiliated territories, the earnings stripping rule is marginal in that it is effective only if the safe harbor limit is exceeded. Hong Kong, Sweden, and the United Kingdom do not have thin-capitalization rules but use other special rules to limit debt financing.

In this paper, we develop a general equilibrium framework with both labor and capital that allows us to analyze the implications of the various thincapitalization rules observed in practice. The model allows us to understand how a country's choice of a thin-capitalization rule influences not just the incidence of internal debt financing but also the transfer pricing behavior of multinationals. In our setting, a host country chooses a thin-capitalization rule to limit income

\footnotetext{
${ }^{7}$ Finland and Norway adopted earnings stripping rules in 2014.
} 
shifting by excessive interest deductions. A multinational firm has a financing subsidiary located in a tax haven and can invest in an operational subsidiary in the host country (high-tax country). The operational affiliate can shift pre-tax income to the tax-haven affiliate by the level of internal debt borrowed from the haven affiliate and the interest rate (transfer price) it pays on this internal debt.

We show the policy, among all the combinations observed in practice, which maximizes the host country's national income is an earnings stripping rule without a safe harbor rule. The reason for our result is as follows. The multinational firm can shift profit either by the abusive interest rate (transfer price) or by internal debt. The latter allows the firm to avoid the tax on the normal rate of return on mobile capital directly, whereas an abusive transfer price is an indirect and more costly way of mitigating the tax wedge both for the firm and society. An earnings stripping rule is more effective at curbing abusive transfer pricing and is therefore a better choice from a host country's perspective.

\subsection{Related literature.}

It is well known that multinational companies shift income by debt and transfer prices from affiliates in low-tax countries to affiliates in high-tax countries. In general, the income-shifting tactics of multinationals can have two effects. The first effect is base erosion. The significance of this effect is evidenced by the BEPS project initiated by the OECD in 2013 (OECD, 2013). The second effect of profit shifting is increased foreign direct investment (FDI) from a higher after-tax return to investment.

There is a small but emerging literature that discusses the welfare effects of tax havens when multinationals use tax-haven conduit companies to shift income. Hines (2010) argues that although the tax avoidance opportunities

presented by tax havens may reduce revenues in high-tax jurisdictions, they may have offsetting effects on FDI that are attractive to the same governments. If 
governments cannot distinguish between mobile and immobile investments, tax havens permit governments to subject immobile investments to higher taxes than mobile investments. Hong and Smart (2010) demonstrate this effect in a model where multinationals shift income by debt from a tax-haven affiliate. They show that providing a tax deduction for interest payments on subsidiary debt allows host countries to maintain or even increase high business tax rates, and to attract more mobile investments from multinationals because the tax deductibility of interest reduces the firm's after-tax cost of capital. The result is higher host welfare.

Gresik et al. (2015) (hereafter GSS) model a host country that chooses a corporate income tax rate and a safe harbor rule and multinationals choose capital, labor, and internal debt levels and the transfer price of debt. They show that the positive investment effect in Hong and Smart (2010) is more likely to dominate in host countries with developed economies and that the negative tax base erosion effect is more likely to dominate in developing economies. The reason is that developed countries have better institutions that curb transfer pricing more effectively. Slemrod and Wilson (2009) use the standard tax competition model but add "parasitic" tax havens to the model in the sense that tax havens are "parasitic" on the tax revenues of non-haven countries. In their model tax havens sell concealment services to taxpayers in non-havens, and non-haven countries must expend real resources to prevent tax base erosion. They show that tax havens increase the social costs that a country incurs when it increases its tax on capital. This aggravates the tax competition problem and results in lower welfare.

There is also a positive literature on the tax sensitivity of debt and the effect of thin-capitalization rules on a firm's financial structure. Huizinga et al. (2008) model the optimal allocation of external debt and find that ignoring international debt shifting as part of the firm's leverage decision understates the impact of national taxes on debt policies by about 25\%. Egger et al. (2010) 
analyze debt shifting by internal debt and find that multinationals have a significantly higher debt-to-asset ratio than national firms, and that this difference is larger in high-tax countries. Møen et al. (2015) show that it is optimal for a multinational firm to shift profit by using both internal debt and external debt. A main result from their empirical analysis is that the shifting of internal and external debt is of about equal importance in German multinationals. ${ }^{8}$

The empirical literature on the effect of different types of thincapitalization rules on the firm's financial structure concludes that thincapitalization rules have a substantial effect on both internal and external leverage. Büttner et al. (2012) study foreign affiliates of German multinationals and find that thin-capitalization rules effectively reduce the incentive to use internal loans for tax planning but result in higher external debt. ${ }^{9}$ Blouin et al. (2014) investigate how thin-capitalization rules worldwide affect the capital structure of foreign affiliates of US multinational firms. They find that restrictions on an affiliate's debt-to-asset ratio reduce this ratio on average by $1.9 \%$, while restrictions on an affiliate's borrowing from the parent debt-to-equity ratio reduce this ratio by $6.3 \%$. Both studies thus find evidence that thincapitalization rules have a substantial effect on the capital structure within multinational firms.

Two other papers analyze rules that restrict leverage ratios in a theoretical framework. Haufler and Runkel (2012) use a tax competition model to show that if countries set tax rates and safe harbor rules, smaller countries have an incentive

${ }^{8}$ See also Desai (2004) for U.S. multinationals and Mintz and Weichenrieder (2010) for an overview. The empirical literature on taxation and capital structure, as reviewed in Auerbach (2002) and Graham (2003), find small effects of tax incentives on capital structure. This is attributed to a lack of variation in tax rates. More recent studies where data encompass the bulk of tax reforms in OECD countries find larger effects.

${ }^{9}$ See also Wamser (2008) and Weichenrieder and Windischbauer (2008). 
to set more permissive safe harbor rules because they face a more elastic tax base. More closely related to our paper is Mardan (2015) who investigates earnings stripping rules and rules in a setting with two countries and capital as the only input. His focus is on how credit market constraints may affect leverage and thincapitalization rules. He finds no clear cut preference for safe harbor or earnings stripping rules. ${ }^{10}$

To our knowledge we are the first to show in a general equilibrium framework with both capital and labor as input choices, with firms engaging in both transfer pricing and debt shifting, and that allows for hybrid as well as traditional rules, that an earnings stripping rules maximizes a host country's national income.

The rest of our paper is organized as follows. Section 2 presents a model in which multinational firms can shift profit with debt financing and transfer prices. To allow for the hybrid policies observed in Bulgaria, Denmark, France, Japan, and the United States, a host country will choose a thin-capitalization policy that consists of both a safe harbor limit and an earnings stripping limit. Section 3 derives the optimal firm responses to all possible host country's thin capitalization policies. Section 4 then describes which limits will be binding in any FDI and labor-market equilibrium. The host country's optimal thin capitalization policy is then derived in section 5. Several extensions of the base model are discussed in section 6 and concluding remarks are offered in section 7 .

\section{A model of profit-shifting via debt and transfer prices.}

We adapt the model in GSS to allow for a host country to distinguish

\footnotetext{
${ }^{10}$ Kalamov (2015) studies the equilibrium choice of safe harbor and earnings stripping rules with two host countries but in a model in which the multinational cannot shift income into a tax haven with transfer pricing.
} 
between the effects of a safe harbor rule and an earnings stripping rule. A multinational firm can invest capital, either equity or debt, in a single host country. All of the FDI is issued by a subsidiary of the multinational located in a tax-haven country that levies a zero tax rate on corporate income.

The host country economy consists of workers, who inelastically supply one unit of labor, and entrepreneurs, who own domestic firms. Domestic firms can employ $L_{d}$ units of labor at a wage rate $w$ to produce $G\left(L_{d}\right)$ units of output that are sold in a competitive market. The output price is normalized to one. The production function, $G(\cdot)$, is strictly increasing and strictly concave in $L_{d}$. The pre-tax profit of a domestic firm is

$$
\pi=G\left(L_{d}\right)-w L_{d}
$$

The host country levies a profit tax rate of $t$ so that domestic firms have a post-tax profit of $(1-t) \pi$.

The multinational firm operates with the production function, $F\left(L_{m}, K\right)$, where $L_{m}$ denotes the amount of host-country labor it employs and $K$ denotes the amount of capital invested in its host country subsidiary. $F(\cdot, \cdot)$ is strictly increasing, strictly concave, and homogeneous of degree 1 in both inputs. The multinational faces the same competitive wage rate, $w$, and sells its output in a competitive market whose price is also normalized to one. Denote the multinational's economic cost of capital by $r$.

The multinational can choose to finance its capital investment with equity, $E$, and/or internal debt, $B$, so that $K=E+B$. In order to focus on the incomeshifting strategies of the multinational firm we focus on the use of internal debt only. By definition, income shifting is done between related parties and the vast majority of thin-capitalization rules in place targets intra-firm transactions and 
internal debt only. ${ }^{11}$

We assume that the multinational's economic cost of capital reflects, in part, a country-specific risk of the investment so that $r$ need not simply equal a worldwide interest rate. The idiosyncratic cost of capital allows the multinational to charge its host country subsidiary an interest rate, $\sigma$, that can differ from $r$. That is, $\sigma$ is the transfer price of internal debt. Allowing the multinational to use its transfer price on debt to shift income out of the host country is the simplest and most direct way to see the linkages between debt-shifting and transfer pricing, and it is consistent with the fact that many countries use arm's-length price auditing standards to the interest rates multinationals charge for internal debt.

The multinational incurs transfer pricing costs of $c(\sigma-r) B$ to reflect any transfer price auditing the host country may conduct. These transfer pricing costs consist of two components. First, the cost function, $c(\cdot)$, is increasing and convex in the difference between $\sigma$ and $r$, which we take to be the arm's-length interest rate. $^{12}$ Second, the multinational's transfer pricing costs are proportional to the amount of debt as the total amount of shifted profit will equal $(\sigma-r) B$.

A key reason for financing a subsidiary with debt instead of equity is that payments on debt are tax deductible expenses while dividend payments to equity holders are not. ${ }^{13}$ In terms of the trade-offs between issuing external debt and

11 The main exceptions are Bulgaria, Denmark, Germany, Spain and Portugal. Norway and Finland, which recently introduced earnings stripping rules, do not restrict external debt.

12 For example, U.K. thin-capitalization laws focus primarily on the transfer pricing issue in that the revenue authority "may challenge interest deductions on the grounds that, based on all of the circumstances, the loan would not have been made at all or that the amount loaned or the interest rate would have been less, if the lender was an unrelated third party acting at arm's length" (Ernst \& Young, 2013, p. 1367).

${ }^{13}$ Davies and Gresik (2003) study the role of debt borrowed from host country investors. 
internal debt, previous studies such as Stonehill and Stitzel (1969) and Chowdhry and Coval (1998) argue that internal debt is really tax-favored equity. However, Chowdry and Nanda (1994) show that internal debt can be issued with the same seniority as external debt. As a result internal debt can create agency costs associated with an increased probability of bankruptcy. Internal debt also generates costs of complying with thin capitalization rules and adjusting managerial incentive contracts. Consistent with Egger et al. (2010), Mintz and Smart (2004), Schindler and Schjelderup (2012) and Mardan (2015), we assume the multinational incurs debt-financing costs of $D(B / K)$ that are strictly increasing and strictly convex in the subsidiary's debt to equity ratio for $B>0$. We also assume that (i) $D(0)=0$, (ii) $D^{\prime}(0)=0$, and (iii) $D^{\prime}(1)=\infty$.

As long as the subsidiary faces the same tax rate on host country profit as do domestic firms, the multinational's after-tax profit is defined as

$$
\Pi=(1-t)\left(F\left(L_{m}, K\right)-w L_{m}-\sigma B\right)+\sigma B-r K-c(\sigma-r) B-D(B / K) .
$$

Notice that the subsidiary's interest expense, $\sigma B$, is tax deductible in the host country. According to (2.2), the multinational can avoid any transfer price costs by setting $\sigma=r$ even if $B>0$ while it can avoid the debt issuance costs only by setting $B=0$. The tax savings from internal debt net of transfer price costs equals $(t \sigma-c) B$, which implies that the unconstrained optimal transfer price satisfies $c^{\prime}=t . \quad$ By the convexity of $c(\cdot), t \sigma>c$ for all $\sigma$ such that $c^{\prime} \leq t$. For any positive values of $K$ and $L_{m}$,

$$
d \Pi=B\left(t-c^{\prime}\right) d \sigma+\left(t \sigma-c-D^{\prime} / K\right) d B=(t \sigma-c) d B>0
$$

for $B=0$ and $c^{\prime} \leq t$. Thus, in the absence of any thin-capitalization rules, a 
multinational that chooses to invest in the host country has an incentive to use some debt financing.

If the host country adopts a safe harbor rule, then the host subsidiary will be able to deduct its interest expense against its host country income only if

$$
B \leq b_{s} K
$$

where $0 \leq b_{s} \leq 1$. If the host country adopts an earnings stripping rule, then the host subsidiary will be able to deduct its interest expense against its host country income only if

$$
\sigma B \leq b_{e}\left(F-w L_{m}\right)
$$

where $0 \leq b_{e} \leq 1$. The term $F-w L_{m}$ represents the host subsidiary's EBITDA so an earnings stripping rule requires that its interest payments do not exceed a given percentage of its pre-tax earnings. Setting $b_{s}=1$ is equivalent to imposing no safe harbor limit on internal debt while setting $b_{e}=1$ is equivalent to letting the multinational strip out all of its pre-tax host country earnings through its internal debt financing. Ineq. (2.4) need not bind for a profit-maximizing firm, even when its host subsidiary is financed entirely with debt. For example, if the multinational employs labor so that $F_{L}=w$, then setting $B=K$ in (2.4) requires $F_{K} \geq \sigma / b_{e}$. With $b_{e}>(1-t)$ and sufficiently costly transfer price regulation, $\sigma$ will be small enough so that (2.4) is slack.

The host country seeks to maximize its national income, $Y$, which is the sum of worker and entrepreneur consumption. Aggregate worker consumption equals wage income, $w$, plus taxes, $T$. Since a profit-maximizing multinational 
will employ labor so that $F_{L}=w$, regardless of the thin-capitalization rule the host country adopts, host tax revenues equal

$$
T=t \pi+t\left(F-w L_{m}-\sigma B\right)=t \pi+t\left(F_{K} K-\sigma B\right)
$$

Entrepreneur income equals $(1-t) \pi$. Thus, host country national income is equal to

$$
Y=w+\pi+t\left(F_{K} K-\sigma B\right)
$$

We do not include a welfare term that weights entrepreneur profit differently from worker income or tax revenues nor do we include a fraction of multinational profit associated with some host country ownership as these extra terms would not change our main result.

\section{Optimal Firm Behavior.}

Allowing for the possibility that a host country imposes safe harbor and earnings stripping rules on the multinational, the firm's profit-maximization problem becomes

$$
\begin{gathered}
\max _{K, L_{m}, B, \sigma}(1-t)\left(F-w L_{m}\right)+t \sigma B-r K-c(\sigma-r) B-D(B / K) \\
\text { s.t. (1) } g_{1}\left(K, L_{m}, B, \sigma\right) \equiv \sigma B-b_{e}\left(F-w L_{m}\right) \leq 0 \\
\text { (2) } g_{2}(B, K) \equiv B-b_{s} K \leq 0 .
\end{gathered}
$$

To solve the multinational's profit-maximization problem, define the Lagrangean to be 


$$
\begin{gathered}
\Lambda=(1-t)\left(F-w L_{m}\right)+t \sigma B-r K-c(\sigma-r) B-D(B / K) \\
-\mu\left(\sigma B-b_{e}\left(F-w L_{m}\right)\right)-\zeta\left(B-b_{s} K\right)
\end{gathered}
$$

where $\mu$ and $\zeta$ are the Lagrange multipliers. The necessary first-order conditions associated with (3.2) are

$$
\begin{array}{ll}
\text { (a) } & \zeta+\mu \sigma=t \sigma-c-D^{\prime} / K, \\
\text { (b) } & B\left(t-c^{\prime}-\mu\right)=0, \\
\text { (c) } & \left(1-t+\mu b_{e}\right)\left(F_{L}-w\right)=0,
\end{array}
$$

and

$$
\text { (d) } \quad F_{K}=\left(r-B D^{\prime} / K^{2}-b_{s} \zeta\right) /\left(1-t+\mu b_{e}\right) \cdot{ }^{14}
$$

In the absence of either a safe harbor rule and/or an earnings stripping rule, the profit-maximizing transfer price and amount of debt satisfy $t=c^{\prime}$ and $t \sigma=c+D^{\prime} / K$. These equations show that the optimal values equate the marginal tax savings with the marginal cost of transfer pricing and debt, respectively. Denote the optimal unconstrained transfer price by $\sigma^{*} . \sigma^{*}$ is greater than $r$ for all $t>0$ and is independent of $K, L_{m}$, and $B$. For any $\sigma$, define $\hat{B}(\sigma)$ to be the solution to the second equation, which is equivalent to (3.3.a) when neither constraint binds. Debt-financing cost function properties (ii) and (iii) imply for all $\sigma \in\left[r, \sigma^{*}\right]$ that $0<\hat{B}(\sigma)<K . \quad \hat{B}(\sigma)$ is strictly increasing on $\left[r, \sigma^{*}\right)$. The optimal unconstrained amount of debt, given $K$, equals $\hat{B}\left(\sigma^{*}\right)$.

\footnotetext{
14 Although $\Pi$ is not globally concave, due to the non-convexity of $D(\cdot)$ with respect to $B$ and $K$, the constraint qualifications are satisfied at all points at which one or both of the constraints binds, except if $B=0$. Since zero internal debt was ruled out as a solution in section 2, (3.3) and the associated complementary slackness conditions will define a solution to (3.1).
} 
Now consider the multinational's profit-maximizing decisions when the host country only imposes a safe harbor rule (i.e., $b_{e}=1$ and $\mu=0$ ). In this case, the multinational's profit-maximizing transfer price is defined from (3.3.b) by $t=c^{\prime}(\sigma-r)$. Thus, the adoption of a safe harbor rule does not affect the firm's optimal transfer price as it is still $\sigma^{*}$. It corresponds to the optimal transfer price under a safe harbor rule in GSS. The safe harbor constraint will bind, at $\sigma^{*}$, only if $\hat{B}\left(\sigma^{*}\right)>b_{s} K$.

Next consider the multinational's profit-maximizing decisions when the host country only imposes an earnings stripping rule (i.e., $b_{s}=1$ and $\zeta=0$ ). If the earnings stripping constraint binds, then (3.3.b) implies that $c^{\prime}=t-\mu<t$ and hence that $\sigma<\sigma^{*}$. Accordingly, introducing an earnings stripping rule gives the multinational the incentive to shift less income with its transfer price. Since earnings stripping rules place a limit on $\sigma B$, the multinational can shift the same amount of income by substituting debt financing for transfer pricing. In the extreme case in which there are no marginal costs associated with internal debt financing, the multinational will completely substitute away from income shifting through its transfer price and will set $\sigma=r$.

Figure 1 illustrates how both constraints interact for fixed (strictly positive) values of $K$ and $L_{m}$. The thick solid line identifies the values of $\sigma$ and $B$ for which the earnings stripping constraint is satisfied with equality, that is $g_{1}=0$. The solid horizontal lines correspond to safe harbor constraints for three different policy parameters, $b_{s}^{\text {high }}>b_{s}^{\text {med }}>b_{s}^{\text {low }}$. The vertical dot-dashed line helps locate $\sigma^{*}$, the profit-maximizing transfer price under a safe harbor rule. The curved dashed lines are isoprofit curves. It is never optimal for a multinational to set $\sigma>\sigma^{*}$ or $B>\hat{B}(\sigma)$.

Higher isoprofit curves correspond to higher profit. The slope of the 
constraint curve, $g_{1}=0$, equals $-B / \sigma$ while the slope of an isoprofit curve equals $-B\left(t-c^{\prime}\right) /\left(t \sigma-c-D^{\prime} / K\right)$. At $\sigma=\sigma^{*}$, each isoprofit curve has a slope of zero while for all $\sigma \in\left[r, \sigma^{*}\right)$ the slope is negative, which means that a multinational will always choose a smaller transfer price under an earnings stripping rule than under a safe harbor rule. And for all $B<\hat{B}(\sigma)$, each isoprofit curve is strictly downward sloping and convex in $\sigma$. Point $a$ corresponds to $g_{1}=$ 0 and $\sigma=r$. When point $a$ is below $\hat{B}(r)$, the isoprofit curve through $a$ is steeper than the earnings stripping curve $\left(g_{1}=0\right)$ because $D^{\prime}>0$. When point $a$ is above $\hat{B}(r), \sigma=r$ cannot be optimal because multinational profit is strictly increasing along $\hat{B}(\sigma)$. This means a multinational still has an incentive to shift income with its transfer price by setting $\sigma$ above $r$ (unless $D^{\prime}=0$ ).

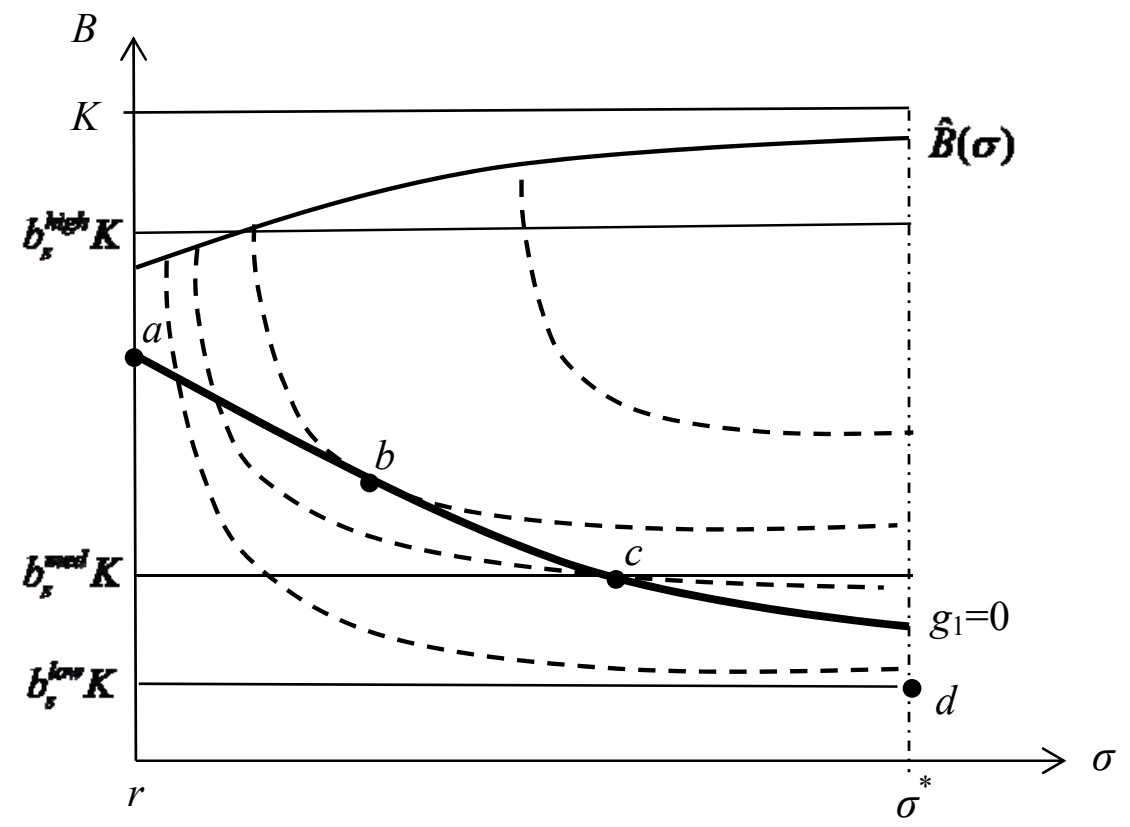

Figure 1: Profit-maximizing transfer prices and debt levels.

This discussion implies the following proposition. 
Proposition 1. A profit-maximizing multinational operating under a binding earnings stripping rule will choose a transfer price strictly between $r$ and $\sigma^{*}$.

Recall from Table 1 that the United States uses an earnings stripping rule which applies only if the safe harbor rule is violated while France allows a firm to satisfy either its safe harbor rule or its earnings stripping rule. Since the earnings stripping constraint is negatively sloped (as illustrated in Figure 1) either type of hybrid policy is weaker than a policy of simply requiring that both constraints be satisfied. With a U.S. or French-type policy, the maximum debt level for which the interest payments would be tax deductible at each transfer price is the larger of the amounts allowed individually by each of the two rules. But this means the optimal transfer price and debt level will be the same as if no earnings stripping rule was in force unless the earnings stripping limit permits higher debt levels than the safe harbor rule for all possible transfer prices. In this case such hybrid policies are identical to imposing only an earnings stripping rule.

Proposition 2. A U.S. or French hybrid policy is equivalent to a policy that uses only a safe harbor rule unless the earnings stripping limit permits higher internal debt levels for all transfer prices. In this latter case, the hybrid policy is identical to one that uses only an earnings stripping rule.

In order for a policy that uses both rules to generate different multinational behavior than a single rule would, the policy must require that both rules be satisfied (in which case the smaller limit on internal debt defines the maximum amount of debt that is permissible for each transfer price). This is the policy Denmark and Japan use.

Figure 1 suggests three possible optimal transfer price-debt pairs: one at 
which only the earnings stripping rule binds because $b_{s}$ is set very high (as at point $b$ ), one at which both constraints bind (as at point $c$ ), and one at which only the safe harbor rule binds (as at point $d$ ). Figure 1 supports the intuition that if the safe harbor rule is weak enough ( $b_{\mathrm{s}}$ is sufficiently close to 1 relative to $b_{e}$ ), then only the earnings stripping rule will affect the multinational's choices. And, if the safe harbor rule is strict enough ( $b_{s}$ is sufficiently close to zero given $b_{e}$ ), then only the safe harbor rule will affect the multinational's choices.

However, Figure 1 does not account for the multinational's overall capital and labor choices nor the general equilibrium effects of choosing $b_{s}$ and $b_{e}$ through the wage rate. For example, consider an increase in $b_{e}$ when both constraints bind (as at point $b$ ). Holding $K$ fixed, a relaxation of the earnings stripping rule implies a higher transfer price. If this change in $b_{e}$ also increases $K$ (as we will show it does) then the safe harbor constraint is indirectly relaxed, and this would imply a lower transfer price. Thus, the general equilibrium implications of safe harbor and earnings stripping rules can differ from their partial equilibrium properties. To capture these effects, we need to characterize equilibrium behavior.

\section{Host Country Equilibria.}

A host country equilibrium consists of profit-maximizing multinational choices, defined by (3.3) and the associated complementary slackness conditions, profit-maximizing employment by domestic firms, defined by

$$
G_{L}\left(L_{d}\right)=w,
$$

and a wage rate that clears the host labor market, 


$$
L_{m}+L_{d}=1
$$

GSS point out that, with a constant returns to scale multinational production function, an equilibrium with positive FDI may not exist. For now, we will assume that, for each value of $b_{s}$ and $b_{e}$, a positive-FDI equilibrium will exist.

Denote the equilibrium that arises when no thin-capitalization rule is in force by $K^{*}, B^{*}, \sigma^{*}, L_{m}^{*}, L_{d}^{*}$, and $w^{*}$. Then define $\bar{b}_{s}=\hat{B}\left(\sigma^{*}\right) / K^{*}$ and $\bar{b}_{e}=\sigma^{*} \hat{B}\left(\sigma^{*}\right) /\left(F\left(K^{*}, L_{m}^{*}\right)-w^{*} L_{m}^{*}\right)$. A safe harbor constraint with $b_{s} \geq \bar{b}_{s}$ will never bind, nor will an earnings stripping constraint with $b_{e} \geq \bar{b}_{e}$.

\subsection{Safe Harbor Only.}

Suppose $b_{s}$ and $b_{e}$ are set so that, in equilibrium, only the safe harbor rule binds. The detailed analysis of this case, as well as the other cases, can be found in the appendix. In order for an equilibrium to exist in which only the safe harbor constraint binds, (A.1) implies that

$$
\sigma^{*} b_{s} \leq b_{e} F_{K}=b_{e}\left(r-b_{s}\left(\sigma^{*} c^{\prime}-c\right)\right) /(1-t) .
$$

Proposition 3. An equilibrium exists in which only the safe harbor rule binds if, and only if, $b_{s}<\bar{b}_{s}$ and $b_{s} \leq r b_{e} /\left((1-t) \sigma^{*}+b_{e}\left(\sigma^{*} c^{\prime}-c\right)\right)$.

The first inequality ensures that the unconstrained optimal level of internal debt is not feasible. The second inequality shows that an equilibrium exists in which only the safe harbor rule binds if $b_{s}$ is sufficiently small. The second inequality is satisfied by some, but not all values of $b_{s}$ and $b_{e}$ because $\sigma^{*}>r$ and $\sigma^{*} c^{\prime}\left(\sigma^{*}-r\right)>c\left(\sigma^{*}-r\right)$ (due to the convexity of $c$ ) imply that the right-hand side 
of the inequality is strictly less than $1 .^{15}$ Intuitively, the existence of this upper bound occurs because an increase in $b_{s}$ causes the multinational to employ more capital (and labor) and the net effect is to decrease the equilibrium return to capital. As the equilibrium return to capital falls, the right-hand side of (4.3) gets smaller so any slack in the earnings stripping constraint is reduced.

The boundary of this safe-harbor equilibrium region is defined by $(1-t) \sigma^{*} b_{s}=b_{e}\left(r-b_{s}\left(\sigma^{*} c^{\prime}-c\right)\right)$. Totally differentiating this equation with respect to $b_{s}$ and $b_{e}$ implies that $d b_{s} / d b_{e}>0$ and $d^{2} b_{s} / d b_{e}^{2}<0$. Thus, higher values of $b_{e}$ increase the range of values of $b_{s}$ such that equilibria exist in which only the safe harbor constraint binds.

The comparative statics analysis with respect to $b_{s}$ also shows that a relaxation of the safe harbor rule, due to an increase in $b_{s}$, causes the equilibrium levels of $K, L_{m}$, and $w$ to increase, $L_{d}$ to decrease, and $\sigma^{*}$ to remain unchanged (see the appendix).

\subsection{Earnings Stripping Only.}

Now suppose that $b_{s}$ and $b_{e}$ are set so that only the earnings stripping constraint binds in equilibrium. Define $\sigma^{E S}$ to be the equilibrium transfer price when only an earnings stripping rule is imposed. The appendix shows in equilibrium (see (A.7)) that

$$
\left(1-t+t b_{e}-b_{e} c / \sigma^{E S}\right) F_{K}=r .
$$

In order for only the earnings stripping constraint to bind, (4.4) implies that

\footnotetext{
${ }^{15}$ The convexity of $c(\sigma-r)$ implies that $\sigma^{*} c^{\prime}-c>r c^{\prime}=r t$ at $\sigma=\sigma^{*}$. Then $(1-t) \sigma^{*}+b_{e}\left(\sigma^{*} c^{\prime}-c\right)>r\left(1-t+b_{e} t\right) \geq r b_{e}$ for all $t \geq 0$.
} 


$$
\sigma^{E S} b_{s} \geq r b_{e} /\left(1-t+t b_{e}-b_{e} c / \sigma^{E S}\right)
$$

Proposition 4. An equilibrium exists in which only the earnings stripping constraint binds if, and only if, $b_{e}<\bar{b}_{e}$ and $b_{s}>r b_{e} /\left(\sigma^{E S}\left(1-t+t b_{e}\right)-b_{e} c\right)$.

Proposition 4 shows that an equilibrium exists in which only the earnings stripping constraint binds only if $b_{\mathrm{s}}$ is sufficiently large. The second inequality is necessary and not sufficient. If the marginal debt-financing costs increase quickly enough, no earnings stripping equilibrium may exist because the multinational's unconstrained profit-maximizing amount of internal debt may be feasible. This possibility is ruled out by the first inequality.

Unlike the safe harbor case, the effect of $b_{e}$ on the equilibrium value of $K$ now depends on the debt-financing costs. However, if the marginal debtfinancing costs are sufficiently small for all $B / K<b_{s}$ (which is an upper bound on the debt to equity ratio in this case), then $K$ will be increasing in $b_{e}$.

\subsection{Safe Harbor and Earnings Stripping.}

Finally, suppose that $b_{s}$ and $b_{e}$ are set so that both constraints bind in equilibrium. Combining the results from Propositions 3 and 4 gives us the conditions under which an equilibrium can exist with both constraints binding.

Proposition 5. An equilibrium exists in which both the safe harbor and earnings stripping constraint bind only if

$$
r b_{e} /\left(\sigma^{*}(1-t)+b_{e}\left(\sigma^{*} c^{\prime}-c\right)\right)<b_{s}<r b_{e} /\left(\sigma^{E S}\left(1-t+t b_{e}\right)-b_{e} c\right) .
$$


Since $\sigma^{E S}<\sigma^{*}$ and $\sigma t-c(\sigma-r)$ is strictly increasing in $\sigma$ for all $\sigma<\sigma^{*}$, the inequalities in Proposition 5 define a non-empty interval. The comparative statics analysis in the appendix shows that both an increase in $b_{s}$ and an increase in $b_{e}$ increase $K, L_{m}$, and $w$. An increase in $b_{s}$ reduces the equilibrium value of $\sigma$ as the multinational now has an incentive to increase its debt financing while reducing its use of its transfer price to shift income out of the host country. In contrast, an increase in $b_{e}$ results in a larger transfer price.

\section{Host Country Welfare.}

We restrict attention to national income maximization. It is affected by FDI in three ways: tax revenues from the FDI, increased wages, and lower profits for domestic entrepreneurs. Given the definition of national income, $Y$, in (2.6), a safe harbor rule implies that

$$
Y^{S H}=w+\pi+t\left(F_{K}-\sigma^{*} b_{s}\right) K
$$

while an earnings stripping rule or a combined safe harbor/earnings stripping rule implies that

$$
Y^{E S}=w+\pi+t\left(1-b_{e}\right) F_{K} K .
$$

Totally differentiating $Y^{S H}$ and using the fact that $L_{d}+L_{m}=1$ in any equilibrium with positive FDI yields

$$
d Y^{S H}=L_{m} d w+t F_{K L} K d L_{m}+t\left(F_{K}-\sigma^{*} b_{s}+F_{K K} K\right) d K-\sigma^{*} t K d b_{s} .
$$


As shown in the appendix, the constant returns to scale properties of $F$ combined with the labor market conditions, $F_{L}=w=G_{L}$ and $L_{d}+L_{m}=1$, imply that $d L_{m}=-F_{K L} d K /\left(F_{L L}+G_{L L}\right)$ and $d w=G_{L L} F_{K L} d K /\left(F_{L L}+G_{L L}\right)$. Thus, one can write $d Y^{S H}$ as

$$
d Y^{S H}=\left[t\left(F_{K}-\sigma^{*} b_{s}\right)-(1-t) F_{K K} G_{L L} K /\left(F_{L L}+G_{L L}\right)\right] d K-\sigma^{*} t K d b_{s}
$$

where the coefficient on $d K$ is strictly positive because $\sigma^{*} b_{s} \leq F_{K}$ in all equilibrium for which the earnings stripping constraint is slack. If $K$ is sufficiently large at $b_{s}=0$, the national income maximizing safe harbor limit can be zero. ${ }^{16}$

Totally differentiating $Y^{E S}$ and using the labor market conditions again implies that

$$
d Y^{E S}=\left[t\left(1-b_{e}\right) F_{K}-\left(1-t\left(1-b_{e}\right)\right) F_{K K} G_{L L} K /\left(F_{L L}+G_{L L}\right)\right] d K-t F_{K} K d b_{e} .
$$

The coefficient on $d K$ is unambiguously positive. Also, notice that (5.5) does not have a $d b_{s}$ term even though $b_{s}$ does affect the equilibrium transfer price when the host country adopts both a safe harbor rule and an earnings stripping rule. When both constraints bind, $\sigma^{*} b_{s}=b_{e} F_{K}$, so the effect of $b_{s}$ on $\sigma^{*}$ is reflected in equilibrium changes in $F_{K}$.

Since a change in $b_{s}$ has no direct effect on national income when both constraints bind in equilibrium and section 4.3 shows that $d K / d b_{s}>0,(5.5)$

\footnotetext{
${ }^{16}$ GSS show that the optimal host country safe harbor rule may support no FDI in equilibrium. In such a case, the minimum value of $b_{s}$ above which FDI is strictly positive will itself be strictly positive.
} 
implies that it is never optimal for the host country to set its safe harbor limit so low that this case arises in equilibrium. Relaxing the safe harbor rule will increase FDI and thus wages and production without any loss in tax revenue since the earnings stripping rule is still binding.

Proposition 6. The optimal values of $b_{s}$ and $b_{e}$ never generate an equilibrium in which both constraints bind.

Proposition 6 calls into question the thin-capitalization policies of Denmark and Japan. Our model predicts that these countries would be better off just imposing an earnings stripping rule.

We now address the question of the optimal host country thincapitalization policy when one allows the host country to use either a single rule or a combination of rules. The host country's tradeoffs are illustrated in Figure 2. The area shaded with dots corresponds to the values of $b_{s}$ and $b_{e}$ for which neither constraint will bind in equilibrium. The region to the left of the red line consists of the values for which only the safe harbor rule will bind in equilibrium and the region to the right of the thick black line consists of the values for which only the earnings stripping constraint will bind in equilibrium. The region between the red and black lines consists of the values for which both constraints will bind in equilibrium. $\quad b_{s}^{*}$ and $b_{e}^{*}$ represent the optimal safe harbor and earnings stripping limits when only that rule is in effect. ${ }^{17}$ The dashed lines represent portions of iso-welfare curves. In the safe-harbor-only region, the iso-welfare curves are vertical since decreases in $b_{e}$ within this region have no effect on national income.

\footnotetext{
${ }^{17}$ If the optimal single-rule policy induces zero FDI in equilibrium, there will be a range of limit values that are optimal. In this case, $b_{s}^{*}$ or $b_{e}^{*}$ represent the maximum value consistent with zero FDI.
} 
Similarly, in the earnings-stripping-only region, the iso-welfare curves are horizontal since increases in $b_{s}$ within this region have no effect on national income.

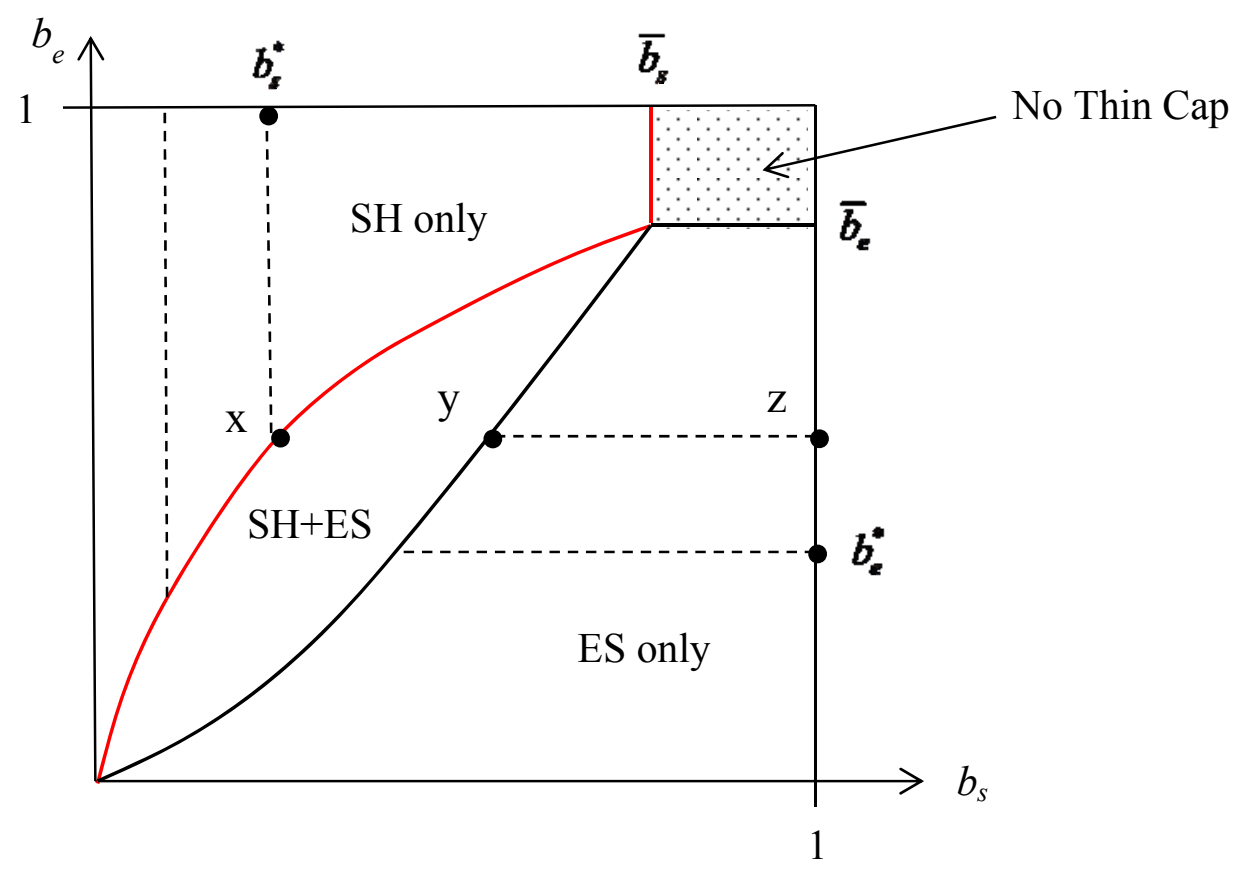

Figure 2: Binding equilibrium thin capitalization rules.

These properties of the iso-welfare curves and Proposition 6 lead to the main result of our paper.

Theorem 1. If $b_{s}^{*}$ or $b_{e}^{*}$ is strictly positive, the optimal thin-capitalization policy for a host country is an earnings stripping rule without a safe harbor rule.

Figure 2 shows why Theorem 1 arises. The policy $\left(b_{s}, b_{e}\right)=\left(b_{s}^{*}, 1\right)$ is the optimal policy when only a safe harbor rule is in effect. National income at $\left(b_{s}^{*}, 1\right)$ is the 
same as at policy $\mathrm{x}$. As long as the optimal stand-alone safe harbor limit is strictly positive, national income at policy $\mathrm{y}$ is strictly greater than at policy $\mathrm{x}$ since $d Y / d b_{s}>0$ in the region where both the safe harbor and earnings stripping constraints bind in equilibrium. (If $b_{s}^{*}=0$, this region is empty.) National income is the same at policies $\mathrm{y}$ and $\mathrm{z}$. Finally, national income is greater at policy $\left(1, b_{e}^{*}\right)$ than at policy $z$ since policy $\left(1, b_{e}^{*}\right)$ is the optimal policy when only an earnings stripping rule is in effect. If $b_{s}^{*}=0$, the optimality of a stand-alone earnings stripping rule continues to hold if $b_{e}^{*}>0$. If both stand-alone limits are zero, then the host country is indifferent to either stand-alone rule.

The reason for this result is that internal debt (i.e., debt shifting) allows the firm to avoid the tax on the normal rate of return on mobile capital directly, whereas an abusive transfer price is an indirect and more costly way of mitigating the tax wedge both for the firm and society. An earnings stripping rule is more effective at curbing abusive transfer pricing and is therefore a better choice from the host country's perspective.

\section{Extensions.}

We now weaken several of the model's assumptions to demonstrate the robustness of Theorem 1.

\subsection{Generalized Welfare Function.}

The national income welfare function weights domestic firm after-tax profits the same as worker income. More generally, one could define host country welfare under binding safe harbor and earnings stripping rules as

$$
Y^{E S}=w+t \pi+t\left(1-b_{e}\right) F_{K} K+\beta(1-t) \pi
$$


where $\beta \in[0,1]$ is the welfare weight on the after-tax income of the domestic entrepreneurs. Now the modified version of (5.5) implies that

$$
\frac{d Y^{E S}}{d b_{s}}=\left[t\left(1-b_{e}\right) F_{K}-\left(1+(1-\beta)(1-t) \frac{\left(1-L_{m}\right)}{L_{m}}-t\left(1-b_{e}\right)\right) \frac{F_{K K} G_{L L} K}{F_{L L}+G_{L L}}\right] \frac{d K}{d b_{s}}
$$

As the coefficient on $d K / d b_{s}$ is strictly positive for all $\beta$, lowering the welfare weight on domestic entrepreneur income does not alter Theorem 1.

Another possibility would be to include multinational profit in the host welfare function. This would be appropriate if host citizens owned stocks in the multinational. Let $\beta^{\prime}<1$ denote the welfare weight on $\Pi$ such that $\beta+\beta^{\prime} \leq 1$. This change would add the term $\beta^{\prime} \cdot d \Pi / d b_{s}$ to (6.2). However, since an increase in $b_{s}$ relaxes the safe harbor constraint, $d \Pi / d b_{s}>0$ when both constraints bind and national welfare is still strictly increasing in $b_{s}$ in this region and Theorem 1 still holds.

\subsection{The multinational production function and debt-financing costs.}

In this subsection, we relax the assumptions that the multinational's production function exhibits constant returns to scale and the debt-financing function depends only on the firm's debt-equity ratio. We now assume that $F\left(L_{m}, K\right)$ is strictly increasing and strictly concave in $L_{m}$ and $K$ and that the debtfinancing costs, $D(B, K)$, can depend on more than $B / K$. We now assume that $D_{B}>0, D_{K}<0, D_{B B}>0, D_{K K}>0$, and $D_{B K}<0$. The change to $F$ implies that we can no longer write the equilibrium value of the subsidiary's pre-tax income as $F_{K} K$ as in (4.3). In an equilibrium in which both constraints bind, it will now be 
the case that $b_{s} \sigma>b_{e} F_{K}$, which means that the multinational is able to shift some economic rents out of the host country prior to taxation. The presence of these rents creates an incentive for the multinational to increase its transfer price, and reduce $K$ in the presence of the earnings stripping rule, and thus can affect the sign of $d K / d b_{s}$. The more general cost-financing function can also affect the sign of $d K / d b_{s}$ through the term $K D_{B K}+b_{s} K D_{B B}$, which is a measure of the convexity of the marginal debt-financing costs when $B=b_{s} K$. As long as the economic rents are not too large and the firm's marginal debt-financing costs are not too convex, $d K / d b_{s}$ will remain positive and Theorem 1 will still hold.

\section{Conclusion.}

Thin-capitalization rules are an important instrument for protecting a host country's corporate tax base, especially in view of the debate on corporate inversions and base erosion by multinationals. In 2013, 57 countries had such rules in place and most of them used safe harbor rules. Recently, some countries have introduced earnings stripping rules. Four countries used earnings stripping rules only in 2013. Norway and Finland followed suit in 2014. Five countries apply a combination of safe harbor and earnings stripping rules.

In this paper, we characterize the set of equilibria for all possible combinations of safe harbor and earnings stripping rules in a general-equilibrium model with both capital and labor choices. Our model allows multinationals to shift income via internal debt financing and transfer pricing. We show that the optimal policy that maximizes the host country's national income is a pure earnings stripping rule without a safe harbor rule.

Our finding follows from the insight that internal debt allows the firm to avoid the tax on the normal rate of return on mobile capital directly, whereas an abusive transfer price is an indirect and more costly way of mitigating the tax 
wedge both for the firm and society. If there are decreasing returns to scale, transfer pricing also lets the multinational shift economic profit, which is not desirable from an optimal tax policy point of view. An earnings stripping rule is more effective at curbing abusive transfer pricing and is therefore a better choice from a host country's perspective. 


\section{References}

Auerbach, A., 2002, Taxation and corporate financial policy, in A.J. Auerbach, and $\mathrm{M}$.

Feldstein, eds.: Handbook of Public Economics, Volume III (North-Holland, New York).

Blouin, J., H. Huizinga, L. Laeven, and G. Nicodème, 2014, Thin capitalization rules and multinational firm capital structure, CESifo Working Paper No. 4695.

Blouin, J. and L. Krull, 2015, Does organizational form affect firms' foreign operations? The role of "Check-the-Box"on multinational tax planning, mimeo, University of Pennsylvania.

Büttner, T., M. Overesch, U. Schreiber, and G. Wamser, 2012, The impact of thin-capitalization rules on the capital structure of multinational firms. Journal of Public Economics 96:930-938.

Chowdhry, B. and J. Coval, 1998, Internal financing of multinational subsidiaries: debt vs. equity. Journal of Corporate Finance 4: 87-106.

Chowdry, B. and V. Nanda, 1994, Financing of multinational subsidiaries: Parent debt vs. external debt. Journal of Corporate Finance 1: 259 - 281.

Davies, R. and T. Gresik, 2003, Tax competition and foreign capital, International Tax and Public Finance 10:127 - 145.

Desai, M. C. Foley, and J. Hines, 2004. A multinational perspective on capital structure choice and internal capital markets. Journal of Finance 59: 2451-2487. ,2006, The demand for tax havens. Journal of Public Economics 90:513-531.

Egger, P., W. Eggert, C. Keuschnigg, and H. Winner, 2010. Corporate taxation, debt financing and foreign plant ownership. European Economic Review 54:96107.

Ernst \& Young, 2013, Worldwide Corporate Tax Guide 2013. EYGM Limited. 
Graham, J., 2003, Taxes and corporate finance: A review, Review of Financial Studies 16:1074-1128.

Gresik, T, D. Schindler, and G. Schjelderup, 2015, The effect of tax havens on host country welfare, CESifo Working Paper No. 5314.

Guitierrez, C., R. Hamzaoui, J. Rienstra, M. Soo, and O. van Boeijen Ostazewska, 2013, Global Corporate Tax Handbook 2013. IFBD Publications BV.

Haufler, A. and M. Runkel, 2012, Firm's financial choices and thin-capitalization rules under corporate tax competition, European Economic Review 56:1087-1103. Hines, J., 2010, Treasure islands, Journal of Economic Perspectives 24: 103-126. Hong, Q. and M. Smart, 2010, In praise of tax havens: International tax planning and foreign direct investment, European Economic Review 54:82 - 95.

Huizinga, H., L. Laeven, and G. Nicodème, 2008. Capital structure and international debt shifting, Journal of Financial Economics 88: 80-118.

Kalamov, Z., 2015, Safe haven vs. earnings stripping rules: A prisoner's

dilemma?, mimeo, ZBW, Leibniz.

Mardan, M., 2015, Why countries differ in thin capitalization rules: The role of financial development, CESifo Working paper No. 5295.

McKinnon, J., 2014, Corporate news: 'Inversion' legislation proposed. Wall Street Journal (September 8), Dow Jones and Company, Inc..

Mintz, J. and M. Smart, 2004, Income shifting, investment, and tax competition: theory and evidence from provincial taxation in Canada. Journal of Public Economics 88:1149-1168.

Mintz, J. and A. Weichenrieder, 2010, The indirect side of direct investment -multinational company finance and taxation. MIT Press, Cambridge.

Møen, J., D. Schindler, G. Schjelderup, and J. Tropina, 2011, International Debt Shifting: Do Multinationals Shift Internal or External Debt? CESifo Working Paper Series No. 3519 
OECD, 2013, Addressing Base Erosion and Profit Shifting, OECD Publishing, http://dx.doi.org/10.1787/9789264192744-en .

Schindler, D. and G. Schjelderup, 2012, Debt shifting and ownership structure.

European Economic Review 56:635-647.

Slemrod, J. and J. Wilson, 2009, Tax Competition with Parasitic Tax Havens,

Journal of Public Economics 93, 1261-1270.

Stonehill, A. and T. Stitzel, 1969, Financial structure and multinational

corporations. California Management Review 12: 91-96.

Wamser, G., 2008, The impact of thin capitalization rules on external debt usage:

a propensity score matching approach, CESifo Working Paper No. 62.

Weichenrieder, A. and H. Windischbauer, 2008, Thin capitalization rules and company responses, CESifo Working paper No. 2456. 


\section{Appendix}

Proposition 1. A profit-maximizing multinational operating under a binding earnings stripping rule will choose a transfer price strictly between $r$ and $\sigma^{*}$.

Proof of Proposition 1. The situation in which the host country adopts only an earnings stripping rule corresponds to setting $b_{s}=1$. With $D^{\prime}>0$, the constraint $B \leq K$ cannot bind so $\zeta=0$. Thus, to the necessary first-order conditions listed in (3.3), we need only add the complementary slackness condition:

(e) $\mu \geq 0$ and $\mu\left(\sigma B-b\left(F-w L_{m}\right)=0\right.$. If the earnings stripping rule is binding, then $\mu>0$ and $\sigma<\sigma^{*} . \mu>0$ also implies via (3.3.b) that $\mu=t-c^{\prime}$. Substituting this value of $\mu$ into (3.3.a) then implies that $\sigma c^{\prime}-c=D^{\prime} / K>0$. At $\sigma=r$, this condition is violated because $c^{\prime}=c=0$. Thus, by the convexity of $c$, $\sigma>r$.

Q.E.D.

\section{Comparative statics when only a safe harbor constraint binds in equilibrium.}

For all equilibria in which only the safe harbor constraint binds, $\mu=0$. Eq. (3.3.a) allows us to solve for $\zeta$ and substitute the expression into (3.3.d), which yields at $B=b_{s} K$,

$$
(1-t) F_{K}=r-b_{s}\left(\sigma c^{\prime}-c\right) .
$$

The debt-financing costs do not influence the equilibrium return on capital because, since $D(\cdot)$ depends only on $B / K$, the increased marginal cost of debt financing from increasing $B$ is exactly offset by the decreased marginal cost of debt financing from increasing $K$. Eq. (3.3.b) implies that the equilibrium transfer price is $\sigma^{*}$, which is independent of $b_{s}$. Differentiating the labor market conditions,(3.3.c), (4.1), and (4.2), with respect to $b_{s}$ then yields 
$F_{L L} d L_{m}+F_{K L} d K-d w=0, G_{L L} d L_{d}-d w=0$, and $d L_{d}=-d L_{m}$. Together these equations imply that $d L_{m}=-F_{K L} d K /\left(F_{L L}+G_{L L}\right)$ and

$$
F_{K L} d L_{m}+F_{K K} d K=F_{K K} G_{L L} d K /\left(F_{L L}+G_{L L}\right) .
$$

Then, totally differentiating (A.1) with respect to $b_{s}$ yields

$$
(1-t) F_{K K} G_{L L} d K /\left(F_{L L}+G_{L L}\right)=-\left(\sigma c^{\prime}-c\right) d b_{s}
$$

or that $d K / d b_{s}>0$.

\section{Comparative statics when only the earnings stripping constraint binds in equilibrium.}

For all equilibria in which only the earnings stripping constraint binds, $\zeta=0$.

Eqs. (3.3.a) and (3.3.b) imply that

$$
\sigma c^{\prime}-c=D^{\prime}(B / K) / K \text {. }
$$

The labor market conditions imply the same relationships between $d K, d L_{m}, d L_{d}$, and $d w$ as in the safe-harbor-only analysis. With only the earnings stripping constraint binding, $\sigma B=b_{e} F_{K} K$, so that (A.4) becomes

$$
\sigma c^{\prime}-c=D^{\prime}\left(b_{e} F_{K} / \sigma\right) / K
$$

and (3.3.d) can be written as

$$
\left(1-t+t b_{e}-b_{e} c / \sigma\right) F_{K}=r .
$$

Totally differentiating (A.5) and (A.6), evaluated at $\sigma=\sigma^{E S}$, with respect to $b_{e}$ then yields

$$
\left(\frac{D^{\prime}}{K^{2}}-\frac{b_{e} F_{K K} G_{L L} D^{\prime \prime}}{\sigma K\left(F_{L L}+G_{L L}\right)}\right) d K+\left(\sigma c^{\prime \prime}+b_{e} F_{K} D^{\prime \prime} /\left(\sigma^{2} K\right)\right) d \sigma=\frac{F_{K} D^{\prime \prime}}{\sigma K} d b_{e}
$$

and

$$
\left(1-t+b_{e}(\sigma t-c) / \sigma\right) \frac{F_{K K} G_{L L}}{\left(F_{L L}+G_{L L}\right)} d K-b_{e} F_{K}\left(\sigma c^{\prime}-c\right) d \sigma / \sigma^{2}=-F_{K}(\sigma t-c) d b_{e} / \sigma .
$$


We can solve (A.7) and (A.8) for $d K / d b_{e}$. The numerator of $d K / d b_{e}$ is equal to

$$
\frac{F_{K}^{2} b_{e} D^{\prime \prime}\left(\sigma t-\sigma c^{\prime}\right)}{\sigma^{3} K}+c^{\prime \prime}(\sigma t-c) F_{K} .
$$

From (3.3.a) and (A.5), $\sigma t-c>D^{\prime} / K=\sigma c^{\prime}-c$ so $\sigma t>\sigma c^{\prime}$ and (A.9) is strictly positive. The denominator of $d K / d b_{e}$ is equal to

$$
\begin{aligned}
{\left[\frac{D^{\prime}}{K^{2}}\right.} & \left.-\frac{D^{\prime \prime}}{K} \cdot \frac{b_{e}}{\sigma} \cdot \frac{F_{K K} G_{L L}}{F_{L L}+G_{L L}}\right] \cdot\left[\frac{-b_{e} F_{K}^{2}}{\sigma^{2}}\left(\sigma c^{\prime}-c\right)\right] \\
& -\left[\sigma c^{\prime \prime}+\frac{b_{e} D^{\prime \prime} F_{K}}{\sigma^{2} K}\right] \cdot\left[\left(1-t+b_{e} t-b_{e} c / \sigma\right) \frac{F_{K K} G_{L L}}{F_{L L}+G_{L L}}\right]
\end{aligned}
$$

The sign of the denominator can be positive or negative as the first and third bracketed terms in (A.10) are positive and the second and fourth terms are negative. However, if $D^{\prime}=0$, then $d K / d b_{e}>0$. Thus, as long as $D^{\prime}$ and $D^{\prime \prime}$ are sufficiently small for all $B / K<b_{s}$, then $d K / d b_{e}$ will continue to be positive.

\section{Comparative statics when both the safe harbor constraint and the earnings stripping constraint bind in equilibrium.}

Eqs. (3.3.a) and (3.3.b) imply that $\zeta=\sigma c^{\prime}-c-D^{\prime}\left(b_{s}\right) / K$. Thus, similar to equilibria in which only the safe harbor constraint binds,

$$
\left(1-t+b_{e}\left(t-c^{\prime}\right)\right) F_{K}=r-b_{s}\left(\sigma c^{\prime}-c\right)
$$

although now $\sigma$ need not equal $\sigma^{*}$. The labor market conditions imply the same relationships between $d K, d L_{m}, d L_{d}$, and $d w$ as in the safe-harbor-only analysis. Now totally differentiating (A.11) with respect to $b_{e}$ yields

$$
\left(1-t+b_{e}\left(t-c^{\prime}\right)\right) F_{K K} G_{L L} d K /\left(F_{L L}+G_{L L}\right)+c^{\prime \prime}\left(b_{s} \sigma-b_{e} F_{K}\right) d \sigma=-\left(t-c^{\prime}\right) F_{K} d b_{e} \cdot(
$$

Because both constraints bind, $b_{s} \sigma=b_{e} F_{K}$ so the $d \sigma$ term is equal to zero and $d K / d b_{e}>0$. Totally differentiating (A.11) with respect to $b_{s}$ yields

$$
\left(1-t+b_{e}\left(t-c^{\prime}\right)\right) F_{K K} G_{L L} d K /\left(F_{L L}+G_{L L}\right)+c^{\prime \prime}\left(b_{s} \sigma-b_{e} F_{K}\right) d \sigma=-\left(\sigma c^{\prime}-c\right) d b_{s} \text {. }
$$


The $d \sigma$ term is again equal to zero and $d K / d b_{s}>0$. Finally, totally differentiating $\sigma b_{s}=b_{e} F_{K}$ yields

$$
b_{s} d \sigma+\sigma d b_{s}=F_{K} d b_{e}+b_{e} F_{K K} G_{L L} d K /\left(F_{L L}+G_{L L}\right) .
$$

Eq. (A.14) implies that $d \sigma / d b_{s}<0$ as relaxing the safe harbor limit leads the multinational to substitute towards more debt financing and away from transfer pricing. Eq. (A.14) also implies that

$$
b_{s} \cdot d \sigma / d b_{e}=F_{K}+b_{e} F_{K K} G_{L L} \cdot\left(d K / d b_{e}\right) /\left(\mathrm{F}_{L L}+G_{L L}\right) .
$$

Substituting (A.12) into (A.15) then implies that

$$
b_{s} \cdot d \sigma / d b_{e}=(1-t) F_{K} /\left(1-t+b_{e}\left(t-c^{\prime}\right)\right)>0 \text {. }
$$

